Supporting Information for:

\title{
New Metastable Packing Polymorph of Donepezil grown on Stable Polymorph Substrates
}

\author{
Yeojin Park ${ }^{1}$, Stephan X.M. Boerrigter ${ }^{2}$, Jisun Yeon ${ }^{1}$, Sun Hye Lee ${ }^{1}$, Sung Kwon Kang ${ }^{3}$, and Eun \\ Hee Lee $e^{1, *}$
}

Table S1: Donepezil polymorphs grown from various levels of supersaturated solution

Figure S1: DSC thermograms of the physical mixtures of forms F and $\mathrm{K}$

Figure S2: Comparison of calculated vs. experimentally obtained powder patterns of form $F$ and the form $\mathrm{K}$ (calculated powder patterns obtained from a single crystal structure analyzed at 173K)

Figure S3: FT-IR spectra of forms $K$ and $F$ showing that the spectra between two forms are similar 
Table S1: Donepezil polymorphs grown from various levels of supersaturated solution

\begin{tabular}{ll}
\hline \multicolumn{1}{c}{ Donepezil (mg/mL in ethanol) } & \multicolumn{1}{c}{ Resulting Forms } \\
\hline $100,110,120,130,150$ & I, II, C, F \\
170 & C \\
200 & I, K+F mixture \\
$300,400,450,500$ & II, K \\
600,700 & $\mathrm{~K}$ \\
\hline
\end{tabular}




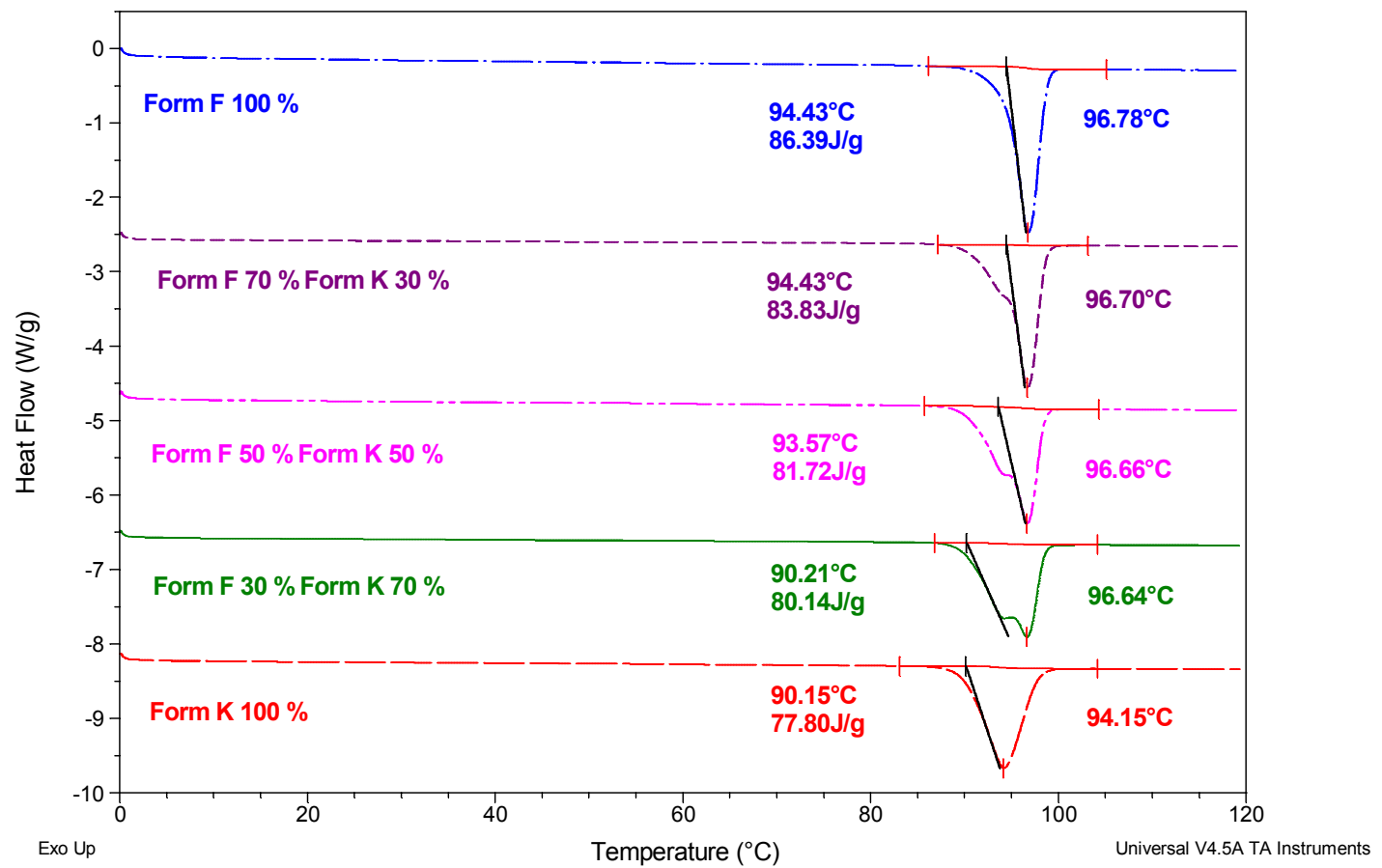

Figure S1: DSC thermograms of physical mixtures of forms F and K 


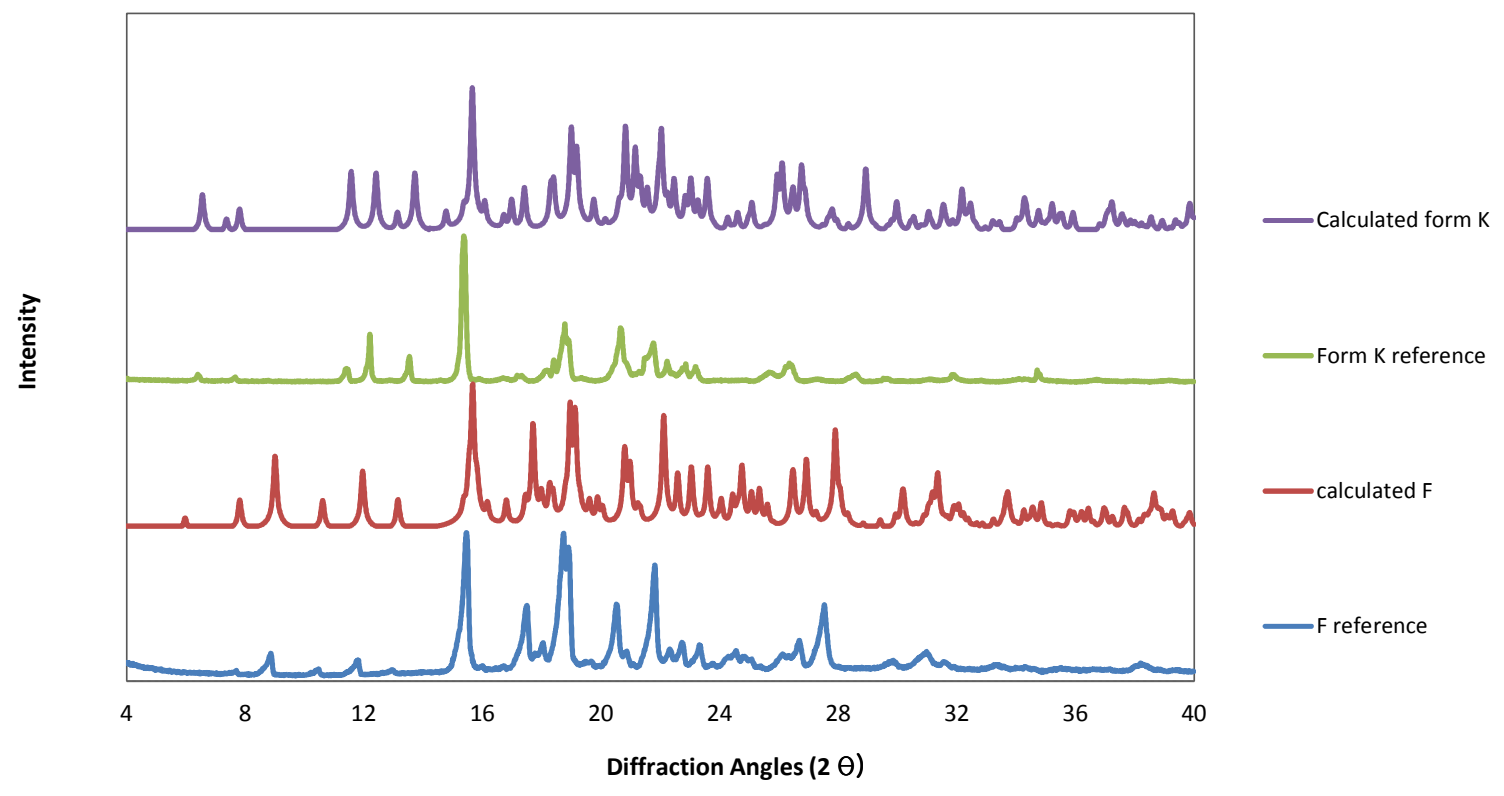

Figure S2: Comparison of calculated vs. experimentally obtained powder patterns of forms $\mathrm{F}$ and $\mathrm{K}$ (calculated powder patterns obtained from a single crystal structure analyzed at $173 \mathrm{~K}$ ) 


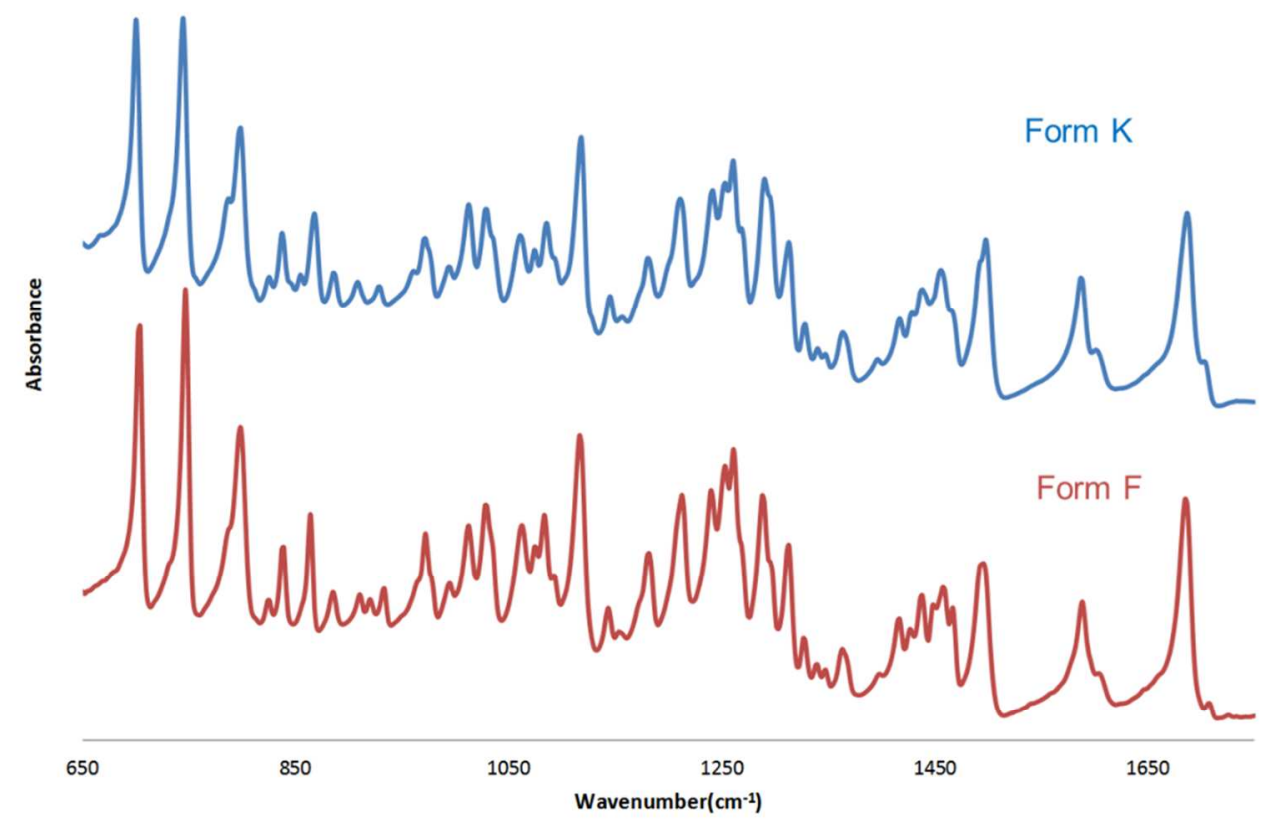

Figure S3: FT-IR spectra of forms K and F showing that the spectra between two forms are similar 